\title{
CHEMOSPHERE
}

\section{Gas chromatography/mass spectrometry applied for the analysis of triazine herbicides in environmental waters}

\author{
W.T. Ma ${ }^{\text {a }}$, K.K. Fu ${ }^{\text {a }}$, Zongwei Cai ${ }^{\text {a,* }}$, G.B. Jiang ${ }^{b}$ \\ a Department of Chemistry, Hong Kong Baptist University, 224 Waterloo Road, Kowloon, Hong Kong SAR, China \\ ${ }^{\mathrm{b}}$ Research Center for Eco-Environmental Sciences, The Chinese Academy of Sciences, 18 Shuangqing Road, Beijing 100085, PR China
}

\begin{abstract}
The excess use of triazine herbicides in agriculture causes severe contamination to the environment especially for ground water. Gas chromatography coupled with mass spectrometry (GC/MS) was used to analyze simazine, atrazine (ATR), cyanazine, as well as the degradation products of ATR such as deethylatrazine and deisopropylatrazine in environmental water samples. These compounds were baseline separated by the established GC method. The water samples were pre-concentrated by solid-phase-extraction (SPE) and analyzed by ion trap MS at sub- to low-ppt levels. Recovery of ATR by the SPE pre-concentration using a $\mathrm{C}_{18}$ cartridge was determined as $90.5 \pm 3.5 \%$. Detection limit of the method using selected ion monitoring technique for ATR was $1.7 \mathrm{ppt}$ when one liter water was analyzed. The relative analytical error for ATR fortified water samples at $200 \mathrm{ppt}$ was $-12.5 \%(n=12)$ with triple analysis and the relative standard deviation was $3.2 \%$. Trace levels of ATR at 3.9 and $9.7 \mathrm{ppt}$ were determined in water samples collected from a reservoir and a river in Hong Kong.
\end{abstract}

(C) 2003 Elsevier Ltd. All rights reserved.

Keywords: GC/MS; Atrazine; Triazine; Solid-phase-extraction (SPE)

\section{Introduction}

Triazine herbicides including atrazine (ATR), simazine and cyanazine help control the growth of weeds through the inhibition of photosynthetic reactions (Kamrin, 1997). Of all these agricultural chemicals, ATR is the most extensively used herbicide in the USA because it is effective in reducing crop losses (Worthing, 1991). ATR degrades slowly in soil through hydrolysis and $N$ dealkylation. Typical degradation products of ATR include deethylatrazine (DEA), deisopropylatrazine (DIA), didealkylatrazine (DDA) and hydroxyatrazine. ATR has a half-life in topsoil of about 60 days, but the half-life is significantly longer in sub-surface soils or in ground water (US Environmental Protection Agency, 1988). The herbicide has a relatively low absorption in soil and easily

\footnotetext{
${ }^{*}$ Corresponding author.

E-mail address: zwcai@hkbu.edu.hk (Z. Cai).
}

migrate through soil and leach into the underground water (Burnside et al., 1963; Schoen and Winterlin, 1987; Geerdink et al., 1989; Buser, 1990; Lee et al., 1999). One of the potential hazards for ATR is its toxic possibility. The persistence of ATR in the environment made it be a Priority A chemical for potential groundwater contamination by the US Environmental Protection Agency (EPA) (US Environmental Protection Agency, 1985). The maximum contamination level in drinking water set by the US EPA was $3 \mu \mathrm{g} / \mathrm{l}$ for ATR (US Environmental Protection Agency, 1985).

Gas chromatography (GC) coupled with nitrogenphosphorus detector (Popl et al., 1983; Steinheimer and Brooks, 1984; Thurman et al., 1990) or mass spectrometer (MS) (Lopez-Avila et al., 1985; Thurman et al., 1990; Durand and Barcelo, 1991; Ahel et al., 1992; Cai et al., 1993; Cassada et al., 1994; Xiong et al., 1998), high performance liquid chromatography (HPLC) (Corcia et al., 1987; Battista et al., 1989; Steinheimer and Ondrus, 1990; Corcia and Marchetti, 1991) and enzyme-linked 
immunosorbent assay (Thurman et al., 1990; Xiong et al., 1998) have been developed for ATR determination in water. The most common sample preparation for trace analysis of ATR in water involves solid-phase-extraction (SPE). The extraction efficiency of SPE is found to be higher than the traditional liquid-liquid extraction (Lee and Stokker, 1986; Thurman et al., 1990; Cassada et al., 1994; Cai et al., 1995). $C_{18}$ bonded silica cartridges and graphitized carbon black cartridges have been reported to be effective to isolate ATR and its degradation products from aqueous matrices (Cai et al., 1993; Cassada et al., 1994).

The object of this work is to qualitatively analyze the triazine compounds by GC/MS and to quantitate ATR at trace concentration levels in water by using SPE and GC/MS analysis.

\section{Experimental section}

\subsection{Reagents and chemicals}

The silica-bonded $\mathrm{C}_{18}$ cartridge $(360 \mathrm{mg})$ was purchased from Waters Corporation (Milford, USA). Native cyanazine, simazine, DEA, DIA and DDA were obtained from Riedel-de Haen (Seeize, Germany). ATR and $\mathrm{D}_{5}$-atrazine were from Crescent Chemical Co., Inc. (Augsburg, Germany) and Dr. Ehrenstorfer $\mathrm{GmbH}$ (Augsburg, Germany) respectively. Organic solvents were HPLC-grade and were purchased from Acros Organics (New Jersey, USA) and Labscan Analytical Science (Patumwan, Bangkok). Stock solution was prepared by dissolving $1.0 \mathrm{mg}$ cyanazine, simazine, DEA, DIA, DDA, ATR, $\mathrm{D}_{5}$-atrazine in $10 \mathrm{ml}$ of ethyl acetate.

The standard solutions of native ATR and $\mathrm{D}_{5}$-atrazine in ethyl acetate were prepared for the determination of relative response factor by diluting the corresponding stock solutions.

\subsection{GClMS analysis}

A Thermo Finnigan Trace GC interfaced with a PolarisQ ion trap mass spectrometer was used for all sample analyses. Water sample extracts and calibration standards were manually injected into a $5 \%$ equivalent polysilphenylene-siloxane GC column (DB-5 column, 30 $\mathrm{m} \times 0.25 \mathrm{~mm}$ i.d., $0.25 \mu \mathrm{m}$ film thickness). The instrument was operated with the Xcalibur software from Finnigan. The conditions of the analysis were as follow: injection volume $(1.0 \mu \mathrm{l})$ with splitless injection, injector temperature $280^{\circ} \mathrm{C}$ and transfer line temperature $300^{\circ} \mathrm{C}$. The carrier gas was helium with flow rate of $1.5 \mathrm{ml} / \mathrm{min}$ at constant flow with vacuum compensation. A temperature programme was used. The initial temperature was
$90{ }^{\circ} \mathrm{C}$ and held for $0.5 \mathrm{~min}$. The temperature was then increased to $160^{\circ} \mathrm{C}$ at $15^{\circ} \mathrm{C} / \mathrm{min}$ and to $280^{\circ} \mathrm{C}$ at the rate of $25^{\circ} \mathrm{C} / \mathrm{min}$ then held for $5 \mathrm{~min}$ isothermal. The mass spectrometer was operated with electron impact ionization (EI) at $70 \mathrm{eV}$, solvent delay was $8 \mathrm{~min}$ to prevent the damage of the MS filament.

The identification of ATR in the environmental water samples was based on the detection of its characteristic $\left[\mathrm{M}-\mathrm{CH}_{3}\right]^{+}$ion peak as well as the comparison of its retention time obtained from the real sample analysis with that of authentic standard. Full-scan MS and MS/MS analyses were conducted to confirm the ATR detection when the ATR levels allowed to carry out experiments. Selected ion monitoring (SIM) mode was used for quantitative analysis of ATR. $\mathrm{D}_{5}$-atrazine was used as internal standard to accomplish a more accurate determination. Two ions at $\mathrm{m} / \mathrm{z} 200$ and $\mathrm{m} / \mathrm{z}$ 205 were selected as the quantitation ions for native ATR and $\mathrm{D}_{5}$-atrazine, respectively.

\subsection{Solid-phase-extraction of environmental water sam- ples}

Three liters of surface water samples were collected in plastic bottles and stored at $4{ }^{\circ} \mathrm{C}$ inside the refrigerator before sample analysis. Prior to the analysis, $200 \mathrm{ppt}$ of D5-atrazine internal standard was added into one liter of the water sample. The $\mathrm{C}_{18}$ SPE cartridge was prewashed with $5 \mathrm{ml}$ of ethyl acetate, methanol and organic-free water with the flow rate of $2 \mathrm{ml} / \mathrm{min}$. The environmental water sample was then flowed through the cartridge with a flow rate of approximate $10-15 \mathrm{ml} /$ min under vacuum. After extraction of the sample, the cartridge was aspirated for 5-10 min to remove residues of water. The cartridge was eluted with $2 \mathrm{ml}$ ethyl acetate twice at a flow rate of $1 \mathrm{ml} / \mathrm{min}$ to extract the ATR absorbed at the stationary phase. The extract was collected in a $5 \mathrm{ml}$ reaction vial. The extract was dried by adding $0.05 \mathrm{~g}$ of anhydrous sodium sulfate to remove the remaining water residue. The extract was then concentrated to approximate $30 \mu \mathrm{l}$ under a slow stream of dry nitrogen.

\subsection{Recovery test}

Standard water sample for recovery test was prepared by fortifying $100 \mathrm{ng}$ of native ATR in $500 \mathrm{ml}$ deionized water. The fortified water sample was treated with the same SPE procedure described above. Finally $100 \mathrm{ng}$ of $\mathrm{D}_{5}$-atrazine was added to the sample extract prior to the GC/MS analysis. The obtained peak area ratio of the fortified ATR to that of the added $\mathrm{D}_{5^{-}}$ atrazine compared with that of standard analysis for determining recovery of the SPE extraction. 


\subsection{Accuracy and precision}

Fortified matrix samples with known amount of ATR were analyzed. The results were used to determine the accuracy and precision of the analytical method. The accuracy is described by relative error that is calculated using the following equation:

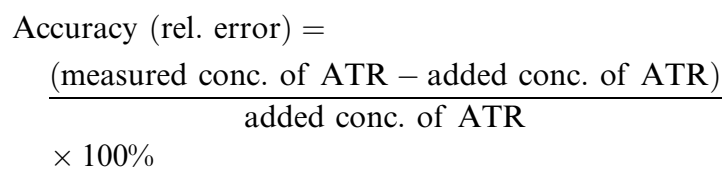

The precision of the analysis is represented by the obtained relative standard deviation from multiple determinations.

\section{Results and discussion}

\subsection{Qualitative and quantitative method development}

Full scan EI-MS of each of the triazine analytes was obtained in order to select ions for their qualitative detection in water. Basically, the peak resulting from the loss of methyl group $\left(\left[\mathrm{M}-\mathrm{CH}_{3}\right]^{+}\right)$was selected because they were found not to interfere each other. Furthermore, the $\left[\mathrm{M}-\mathrm{CH}_{3}\right]^{+}$fragment ion peaks of ATR, cyanazine, DEA and $\mathrm{D}_{5}$-atrazine were the most abundant peaks under the EI-MS conditions. The ions selected for ATR, simazine, cyanazine, DEA, DIA and $\mathrm{D}_{5}$-atrazine were at $\mathrm{m} / \mathrm{z} 200.0, \mathrm{~m} / \mathrm{z} 186.0, \mathrm{~m} / \mathrm{z} 225.0, \mathrm{~m} / \mathrm{z} 172.0, \mathrm{~m} / \mathrm{z}$ 158.0 and $m / z$ 205.0, respectively. A combined mass chromatogram obtained from the detection of the selected ions by injecting a stock solution containing all analytes is demonstrated in Fig. 1. The GC/MS result indicated that by using the established chromatographic conditions, ATR, simazine, cyanazine, DEA and DIA were base line separated (Fig. 1). The retention time of the analytes were 9.40, 9.59, 10.46, 10.56 and $12.22 \mathrm{~min}$ respectively. Base line separation for these triazines is important because the compounds have similar structures and they all contain same core triazine structure. This structural similarity may result in the formation of same fragment ion during the EI-MS analysis and thus cause cross-interference. Therefore, the chromatographic separation plays significant role for the trace detection of the triazine herbicides and their degradation products.

The developed GC/MS method was applied to analyze the environmental water samples collected from Shing Mun reservoir and Lam Tsuen river in Hong Kong. Simazine, cyanazine, DEA and DIA were not detected in the concentrated SPE sample extracts, while a small peak of ATR was observed at $\mathrm{m} / \mathrm{z} 200$ and at its retention time. Therefore, a quantitative assay was subsequently developed for ATR by using SIM technique.

The quantitation of ATR is based on the method of internal standard that was added to the water sample prior to extraction. The use of corresponding isotopelabelled compound as internal standard provides better accuracy and precision for the quantitation of analyte at ultratrace levels in complex matrices because the internal standard has similar chemical and physical properties as the analyte (Cai et al., 1993; Cassada et al., 1994).

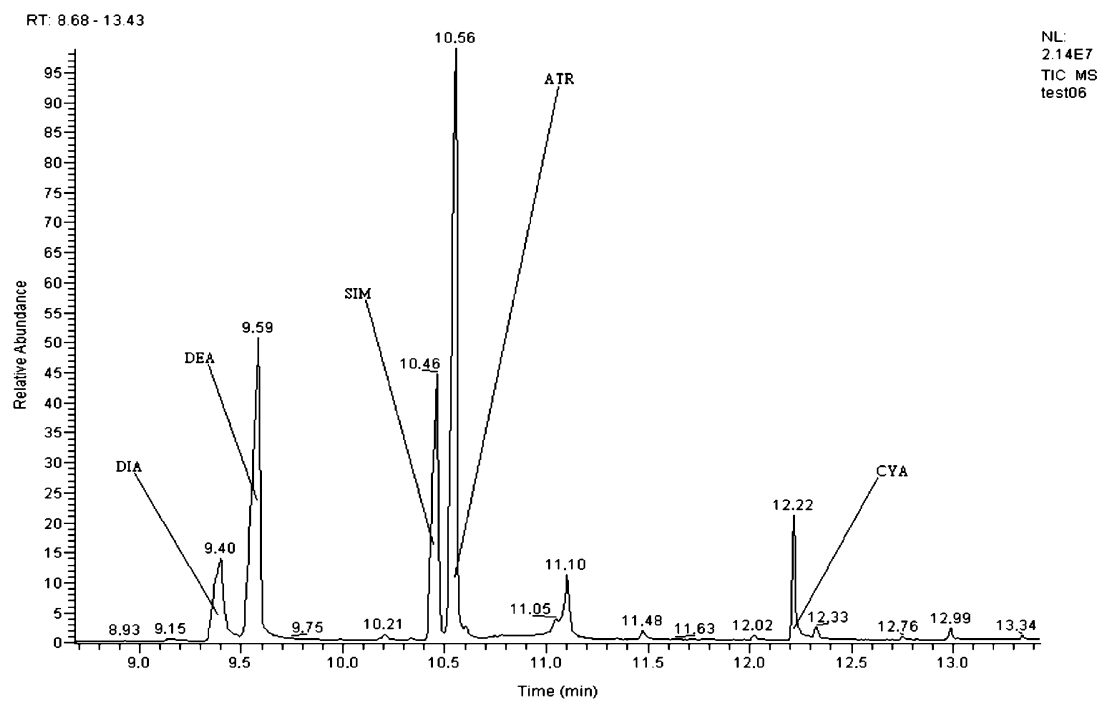

Fig. 1. Gas chromatographic separation of triazine compounds including cyanazine, atrazine, simazine, deethylatrazine and deisopropylatrazine. 
Deuterium labelled ATR $\left(\mathrm{D}_{5}\right.$-atrazine) was selected for the quantitation of ATR in water. The isotopically labelled internal standard recovered in a comparable way as the native analyte during the SPE procedure and GCl MS analysis. The analytical error can thus be significantly reduced. The quantitative method was based on the SIM technique in which the most abundant ions of $m / z 200$ (for ATR) and $m / z 205$ (for $\mathrm{D}_{5}$-atrazine) were used. The EI-mass spectrum of $\mathrm{D}_{5}$-atrazine shows no significant signals at $m / z 200$ that was selected as the quantitative ion for native ATR (Fig. 2). Thus, the internal standard does not interfere with the analysis of native ATR when both compounds are present in sample extract. Similarly, native ATR does not contain the signal at $m / z 205$.

\subsection{Recovery and detection limit}

SPE provides capabilities for both pre-concentration and clean up for the samples. The analyte can be transferred from one matrix to another matrix to facilitate the detection by different instruments. SPE using the $\mathrm{C}_{18}$ cartridge was found to be suitable for the extraction of ATR from water. The averaged inter-day recovery of the SPE procedure was $90.5 \pm 3.5 \%$. The recovery was averaged from triple analysis of three sets of samples containing $100 \mathrm{ng}$ ATR in $500 \mathrm{ml}$ water.

The instrumental detection limit for ATR was 0.05 ng/injection, which corresponds to a procedure detection limits of 5 and $1.67 \mathrm{ppt}$ when the water sample volumes were 300 and $1000 \mathrm{ml}$, respectively, because the injection volume was $1 \mu \mathrm{l}$ out of the final $30 \mu \mathrm{l}$ of the sample extract. The procedure detection limit can be lowered by analyzing a larger volume of water sample.

\subsection{Method accuracy and precision}

Results of the analysis of standard water samples containing ATR at $200 \mathrm{ppt}$ are listed in Table 1. The results indicate that the isotope internal standard method provided good accuracy with relative error $<15 \%$. The precision of the method given as relative standard deviation (RSD) is less than $4 \%$, with triple analysis of four standard water samples.

\subsection{Determination of atrazine levels in environmental waters}

Environmental water samples from Shing Mun reservoir and Lam Tsuen river in Hong Kong were collected for the analysis of the herbicides on 24th February, 2002 and 8th March, 2002, respectively. The reasons for choosing these sites for ATR analysis were that they are susceptible to ATR contamination. In Hong Kong, most of the drinking water are supplied from Dongjiang river, Gongdong, Mainland China and the water is temporarily stored inside the Shing Mun reservoir. Although ATR is one of the monitoring compounds by the Water Service Department of Hong Kong Government, no significant levels of ATR in the water from Dongjiang river had been detected (Hong Kong Water Service Department, 1992). The Dongiiang river, however, is reported to be
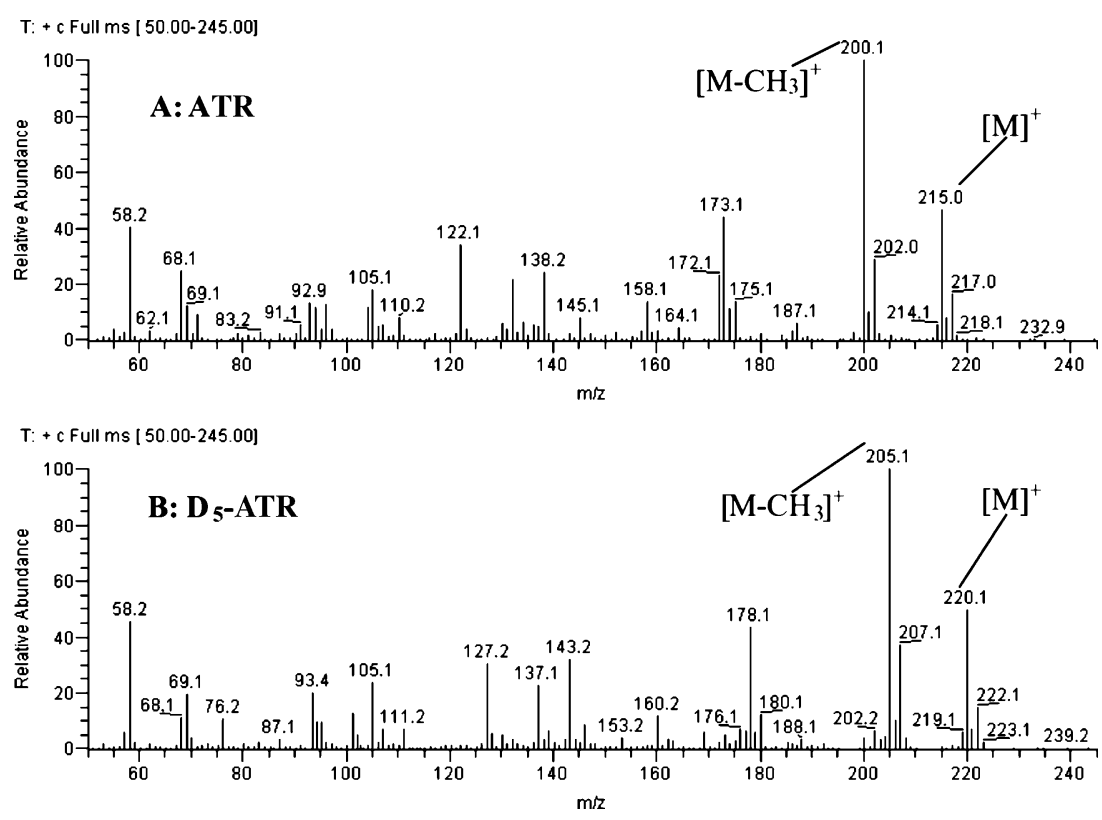

Fig. 2. Electron impact ionization (EI) mass spectra of native atrazine (A) and $\mathrm{D}_{5}$-atrazine (B). 
Table 1

Accuracy and precision data for atrazine analysis in water (200 ppt added) by solid-phase-extraction and GC/MS

\begin{tabular}{|c|c|c|c|c|}
\hline Analysis & Sample 1 (ppt) & Sample 2 (ppt) & Sample 3 (ppt) & Sample 4 (ppt) \\
\hline 1 & 176.7 & 181.5 & 170.8 & 167.8 \\
\hline 2 & 177.4 & 184.5 & 175.7 & 168.6 \\
\hline 3 & 177.9 & 180.4 & 173.1 & 165.5 \\
\hline Average concentration (ppt) & \multicolumn{4}{|c|}{175.0} \\
\hline Relative error $(\%)$ & \multicolumn{4}{|c|}{-12.5} \\
\hline $\mathrm{SD}^{\mathrm{a}}$ & \multicolumn{4}{|c|}{5.7} \\
\hline $\operatorname{RSD}^{\mathrm{b}}(\%)(n=12)^{\mathrm{c}}$ & \multicolumn{4}{|c|}{3.2} \\
\hline
\end{tabular}

${ }^{\mathrm{a}}$ Standard deviation.

${ }^{\mathrm{b}}$ Relative standard deviation.

${ }^{\mathrm{c}}$ Number of determinations (triple analysis of four samples).

polluted by industrial and agricultural facilities. Some residual herbicides might be run-off to the river and finally be transported to Hong Kong. For Lam Tsuen river, there is a large agricultural area nearby and the used herbicides by farmer during the spring time might also be directly run-off to the river. Therefore, these two water sources have a chance of ATR contaminations.

Initially, $300 \mathrm{ml}$ water sample was extracted and analyzed. Although the peak of ATR was barely observed, its integration was difficult because the signal to noise $(\mathrm{S} / \mathrm{N})$ ratio was less than 3 . This indicates that the ATR concentration was lower than the method detection limit when $300 \mathrm{ml}$ water was extracted. Therefore, one liter water sample was subsequently used for the analysis. The analytical results indicated that ATR indeed presented in water samples from both sources at trace levels (Table 2). The averaged ATR concentration levels were 3.9 and $9.7 \mathrm{ppt}$ in the water samples collected from Shing Mun reservoir and Lam Tsuen river, res-

Table 2

Atrazine concentrations $\left(C_{x}\right)$ in water samples from Shing Mun reservoir and Lam Tsuen river with $200 \mathrm{ppt} \mathrm{D}_{5}$-atrazine fortified as internal standard

\begin{tabular}{llc}
\hline Analysis & $\begin{array}{l}\text { Shing Mun reservoir } \\
\mathrm{C}_{x}(\mathrm{ppt})\end{array}$ & $\begin{array}{l}\text { Lam Tsuen river } \\
\mathrm{C}_{x}(\mathrm{ppt})\end{array}$ \\
\cline { 2 - 3 } Blank & ${\mathrm{N} / \mathrm{D}^{\mathrm{a}}}^{\mathrm{N} / \mathrm{D}^{\mathrm{a}}}$ \\
\hline 1 & 3.4 & 8.9 \\
2 & 4.1 & 7.8 \\
3 & 4.2 & 10.4 \\
4 & 4.0 & 12.1 \\
5 & - & 8.9 \\
Mean & 3.9 & 9.7 \\
$\mathrm{SD}^{\mathrm{b}}$ & 0.3 & 1.5 \\
$\mathrm{RSD}^{\mathrm{c}}(\%)$ & 7.9 & 15.6 \\
\hline
\end{tabular}

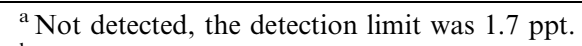

${ }^{\mathrm{b}}$ Standard deviation.

${ }^{\mathrm{c}}$ Relative standard deviation. The number of GC/MS analysis were four and five for the water samples collected from Shing Mun reservoir and Lam Tsuen river, respectively. pectively. The results satisfy well the quality set by the Hong Kong Water Service Department regulating that ATR concentration must be lower than $2 \mathrm{ppb}$ in drinking water.

\section{Conclusion}

By using the method of GC/MS, the separation of different triazine compounds including ATR, simazine, cyanazine, DEA and DIA was accomplished. GC/MS together with a SPE procedure using a $\mathrm{C}_{18}$ cartridge lead to the detection of atrazine in water at ultratrace levels with good accuracy and precision. The method has already been implemented for determining atrazine in environmental water samples. This method might also be extended to the determination of other triazine compounds that may present in environmental waters.

\section{Acknowledgements}

This work was supported by Faculty Research Grant (FRG/01-02/II-34) Hong Kong Baptist University and Equipment Grant-Central Allocation of the Research Grants Council, University Grants Committee of Hong Kong (HKBU-1/00C).

\section{References}

Ahel, M., Evans, K.M., Fileman, T.W., Mantoura, R.F.C., 1992. Determination of atrazine and simazine in estuarine samples by high-resolution gas chromatography and nitrogen selective detector. Anal. Chim. Acta 268, 195-204.

Battista, M., Corcia, A.D., Marchetti, M., 1989. Extraction and isolation of triazine herbicides from water and vegetables by a double trap tandem system. Anal. Chem. 61, 935939.

Burnside, O.C., Fenster, C.R., Wicks, G.A., 1963. Dissipation and leaching of monuron, simazine and atrazine in Nebraska soils. Weed Sci. 11, 209-213. 
Buser, H.R., 1990. Atrazine and others s-triazine herbicides in lakes and in rain in Switzerland. Environ. Sci. Technol. 24, 1049-1058.

Cai, Z., Ramanujam, V.M.S., Giblin, D.E., Gross, M.L., 1993. Determination of atrazine in water at low- and sub-partsper-trillion levels by using solid-phase-extraction and gas chromatography/high-resolution mass spectrometry. Anal. Chem. 65, 21-28.

Cai, Z., Gross, M.L., Spalding, R.F., 1995. Liquid solid extraction and fast atom bombardment high-resolution mass spectrometry for the determination of hydroxyatrazine in water at low-ppt levels. Anal. Chim. Acta 304, 67-73.

Cassada, D.A., Spalding, R.F., Cai, Z., Gross, M.L., 1994. Determination of atrazine, deethylatrazine and deisopropylatrazine in water and sediment by isotope dilution gas chromatography-mass spectrometry. Anal. Chim. Acta 287, $7-15$.

Corcia, A.D., Marchetti, M., 1991. Multiresidue method for pesticides in drinking water using a graphitized carbon black cartridge extraction and liquid chromatographic analysis. Anal. Chem. 63, 580-585.

Corcia, A.D., Marchetti, M., Samperi, R., 1987. Rapid determination of simazine and atrazine in water at the parts per trillion level. Extraction by a miniaturized Carbopack B trap follow by high-performance liquid chromatography. J. Chromatogr. 405, 357-363.

Durand, G., Barcelo, D., 1991. Confirmation of chlorotriazine pesticides, their degradation products and organophosphorus pesticides in soil samples using gas-chromatography mass-spectrometry with electron-impact and positive-ion and negative-ion chemical ionization. Anal. Chim. Acta 243, 259-271.

Geerdink, R.B., Balkom, C.A.A.V., Brouwer, H.J., 1989. Determination of phenoxyacid herbicides in water-polymeric pre-column preconcentration and tetrabutyl-ammonium ion-pair separation on a PRP-1 column. J. Chromatogr. 481, 275-285.

Hong Kong Water Service Department, 1992. Dongjiang Water Quality for the Period April 2001-March 2002 as received in Hong Kong at Muk Wu Pumping Station. Available from $<$ http://www.info.gov.hk/wsd/wq/DongjiangWater2002e_3. $\mathrm{pdf}>$.
Kamrin, M.A., 1997. Pesticide Profiles; Toxicity, Environmental Impact, and Fate. Lewis, Boca Raton, FL.

Lee, H.B., Stokker, Y.D., 1986. Analysis of 11 triazines in natural-waters. J Assoc. Off. Anal. Chem. 69, 568-572.

Lee, S.H., Lee, S.K., Park, Y.H., Kim, J., Lee, D.W., 1999. Preconcentration and detection of herbicides in water by using the on-line SPE-HPLC system and photochemical reaction. Bull. Korean Chem. Soc. 20, 1165-1171.

Lopez-Avila, V., Hirata, P., Kraska, S., Flanagan, M., Taylor, J.J., Hern, S.C., 1985. Determination of atrazine, lindane, pentachlorophenol and diazinon in water and soil by isotope dilution gas chromatograph/mass spectrometer. Anal. Chem. 57, 2797-2801.

Popl, M., Voznakova, Z., Tatar, V., Standova, J., 1983. Determination of triazine in water by GC and LC. J. Chromatogr. Sci. 21, 39-42.

Schoen, S.R., Winterlin, W.R., 1987. The effect of various soil factors and amendments on the degradation of pesticide mixtures. J. Environ. Sci. Health Ser. B 22 (3), 347-377.

Steinheimer, T.R., Brooks, M.G., 1984. Development and evaluation of a gas chromatographic method for the determination of triazine herbicides in natural water samples. Int. J. Environ. Anal. Chem. 17, 97-111.

Steinheimer, T.R., Ondrus, M.G., 1990. USGS/Water Resources Investigation Report 894193.

Thurman, E.M., Meyer, M., Pomes, M., Perry, C.A., 1990. Enzyme-linked-immunosorbent-assay compared with gaschromatography mass-spectrometry for the determination of triazine herbicides in water, A.P. Schwab. Anal. Chem. 62, 2043-2048.

US Environmental Protection Agency, 1985. EPA draft final list of recommendations for chemicals in the National Survey for Pesticides in Groundwater. Chem. Regul. Rep. 9 (34), 1033.

US Environmental Protection Agency, 1988. Atrazine-health Advisory. Office of Drinking Water, Washington, DC. p. 861.

Worthing, C.R., 1991. The Pesticide Manual, ninth ed. British Crop Protection Council.

Xiong, G., Liang, J., Zon, S., Zhang, Z., 1998. Microwaveassisted extraction of atrazine from soil followed by rapid detection using commercial ELISA kit. Anal. Chim. Acta 371, 97-103. 